\title{
High proportion of healthcare-associated urinary tract infection in the absence of prior exposure to urinary catheter: a cross-sectional study
}

Ilker Uçkay ${ }^{1,2,3}$, Hugo Sax ${ }^{1,11}$, Angèle Gayet-Ageron ${ }^{1}$, Christian Ruef ${ }^{4,12}$, Kathrin Mühlemann ${ }^{{ }^{\wedge}}$, Nicolas Troillet ${ }^{6}$, Christiane Petignat ${ }^{7}$, Enos Bernasconi ${ }^{8}$, Carlo Balmelli ${ }^{7}$, Andreas Widmer ${ }^{9}$, Karim Boubaker ${ }^{10,13}$, Didier Pittet ${ }^{1,3^{*}}$ for the Swiss-NOSO network

\begin{abstract}
Background: Exposure to urinary catheters is considered the most important risk factor for healthcare-associated urinary tract infection (UTI) and is associated with significant morbidity and substantial extra-costs. In this study, we assessed the impact of urinary catheterisation (UC) on symptomatic healthcare-associated UTI among hospitalized patients.

Methods: A nationwide period prevalence survey of healthcare-associated infections was conducted during 1 May to 30 June 2004 in 49 Swiss hospitals and included 8169 adult patients (4313 female; 52.8\%) hospitalised in medical, surgical, intermediate, and intensive care wards. Additional data were collected on exposure to UC to investigate factors associated with UTI among hospitalised adult patients exposed and non-exposed to UC.

Results: 1917 (23.5\%) patients were exposed to UC within the week prior to survey day; 126 (126/8169; 1.5\%) developed UTI. Exposure to UC preceded UTI only in 73 cases (58\%). By multivariate logistic regression analysis, UTI was independently associated with exposure to UC (odds ratio [OR], $3.9[95 \% \mathrm{Cl}, 2.6-5.9])$, female gender (OR, 2.1 [95\% Cl, 1.4-3.1]), an American Society of Anesthesiologists' score > 2 points (OR, 3.2 [95\% Cl, 1.1-9.4], and prolonged hospital stay $>20$ days $(\mathrm{OR}, 1.9$ [95\% Cl, 1.4-3.2]. Further analysis showed that the only significant factor for UTI with exposure to UC use was prolonged hospital stay $>40$ days $(\mathrm{OR}, 2.9[95 \% \mathrm{Cl}, 1.3-6.1]$, while female gender only showed a tendency $(\mathrm{OR}, 1.6[95 \% \mathrm{Cl}, 1.0-2.7]$. In the absence of exposure to UC, the only significant risk factor for UTI was female gender (OR, 3.3 [95\% Cl, 1.7-6.5]).

Conclusions: Exposure to UC was the most important risk factor for symptomatic healthcare-associated UTI, but only concerned about half of all patients with UTI. Further investigation is warranted to improve overall infection control strategies for UTI.
\end{abstract}

Keywords: Prevalence, Urinary catheter, Acute care, Urinary tract infection, Nosocomial, Risk factors

\footnotetext{
* Correspondence: didier.pittet@hcuge.ch

Deceased

'Infection Control Programme and WHO Collaborating Centre on Patient

Safety, University of Geneva Hospitals and Faculty of Medicine, 4 Rue

Gabrielle Perret-Gentil, 1211, Geneva 14, Switzerland

${ }^{3}$ Department of Infectious Diseases, University of Geneva Hospitals and

Faculty of Medicine, Geneva, Switzerland

Full list of author information is available at the end of the article
} 


\section{Background}

Indwelling urinary catheters (UC) are an integral part of medicine today [1,2], and as many as one-quarter of all patients require their placement during hospital stay [3]. Exposure to UC is currently considered the most important risk factor for healthcare-associated urinary tract infection (UTI) and is associated with significant morbidity [3-5] and substantial extra-costs [6,7]. The literature suggests that the rate of UTI acquisition is 5\% per day of UC use [3]. Despite the harm potential and the existence of educational programmes to prevent unnecessary catheterisation, UC continues to be frequently used or maintained without clear indications $[3,4,8]$.

In Switzerland, nationwide period prevalence surveys of healthcare-associated infections have been regularly conducted for the past 15 years and provide a unique opportunity to gain insight into their epidemiology [9-12]. During the 2004 survey, we collected additional data on exposure to UC and evaluated factors associated with UTI among hospitalised adult patients exposed and non-exposed to UC.

\section{Methods}

\section{Setting and study organization}

Five nationwide period prevalence surveys of healthcareassociated infections have been conducted since 1996 in Switzerland in over 100 acute care hospitals [9-12]. These were coordinated by SwissNOSO, an independent panel of experts in infectious diseases and hospital epidemiology representing all Swiss university-affiliated hospitals. Hospital participation was voluntary. Observers were infection control practitioners who attended at least three one-day training sessions during which detailed documentation was provided in their native language, including the study protocol, standardised case report form, written definitions for all study variables, practical exercises, and code lists [9]. The prevalence study was scheduled to assess all healthcare-associated infections. All nurses and physicians performing the study were trained to distinguish between community and healthcare-associated infections; the latter was defined as symptomatic infection occurring after $48 \mathrm{~h}$ of hospital admission. Infection control practitioners from centres with and without experience in prevalence studies were grouped as study teams and supervised by an infection control physician at each centre $[9,12]$.

\section{Study population and methodology}

All patients hospitalised for at least $24 \mathrm{~h}$ during the survey conducted in May-June 2004 were assessed using a standardised case report form. Dermatological, ophthalmological, paediatric, and psychiatric wards were excluded, as well as long-term care sectors, defined as wards with a median hospital stay $>30$ days. In each hospital, one or several teams of two trained observers with experience in infection control reviewed simultaneously all medical and nursing charts and evaluated patients for the presence of healthcare-associated infections and potential risk factors within a fixed time window, defined as the survey day plus the six previous days. Observers rated their interpretation of chart data on a six-point Likert scale $(1=$ strongly disagree; $6=$ strongly agree). All results were checked by the data manager and physicians in the study centre for plausibility and completeness, and corrected if necessary. The following variables were assessed for each patient: gender; age; immune suppression; hemiplegia; surgery; antibiotic use; hospital size; ward type; and length of hospital stay at time of survey. All non-surgical wards, e.g., neurology, rheumatology, were classified as medical wards. Acuity and severity of the underlying illness were assessed by the American Association of Anesthesiologists' (ASA) score [13], McCabe and Jackson classification [14], Charlson comorbidity index [15], and nursing workload on survey day [16].

\section{Definitions}

Definitions for healthcare-associated infections were adapted from those of the United States Centers for Disease Control and Prevention (CDC) [17] as previously described $[9,11]$. UTI was the primary outcome and defined as an infection occurring after $48 \mathrm{~h}$ of hospitalisation, unless the patient was transferred from another hospital and cumulative hospital stay reached $48 \mathrm{~h}$. Clinical (dysuria, pollakisuria, fever or shivering), laboratory (urine sedimentation profiles, urinary tract cultures), medical and/or radiological data (ultrasound or computed tomography scans) were required for the confirmation of infection in the absence of other signs or explications. Only the first episode of symptomatic UTI for each patient was recorded. Asymptomatic urinary tract colonization (CDC code, UTI-ASB) was not considered as UTI $[9,10]$. Previous exposure to UC was the secondary outcome. Exposure to UC, intensive care, and antibiotics were only considered when they lasted for at least $24 \mathrm{~h}$. A condom collection system was not considered as UC. Duration of exposure to UC was censored at 30 days. Surgery was defined as any procedure performed in the operating room within 30 days prior to survey day.

\section{Statistical analysis}

The primary outcome was the occurrence of symptomatic UTI. First, we compared patients with and without UTI by using Chi-2 or Fisher's exact tests for categorical variables. We used Student's $t$-test or the non-parametric Mann-Whitney test to compare continuous variables. To take into account hospital clustering, we used a logistic regression model with a random effect at the hospital level (cluster effect) to assess the independent association between the main predictor (previous exposure to UC) and UTI after adjustment for the main confounders (gender, age, severity scores [McCabe, ASA], length of hospital stay, 
Table 1 Patient characteristics according to the presence of healthcare-associated urinary tract infection (UTI) $(n=8169)$, Swiss-NOSO Nationwide Prevalence Study, 2004

\begin{tabular}{llll}
\hline & $\begin{array}{l}\text { UTI } \\
(\mathbf{n = 1 2 6 )}\end{array}$ & $\begin{array}{l}\text { No UTI } \\
(\mathbf{n = 8 0 4 3 )}\end{array}$ & P value \\
\hline Urinary catheter exposure (\%) & & & $<\mathbf{0 . 0 0 1}$ \\
$\quad$ Yes & $73(57.9)$ & $1912(23.8)$ & \\
No & $53(42.1)$ & $6131(76.2)$ & \\
Gender, female (\%) & $85(67.5)$ & $4228(52.6)$ & $\mathbf{0 . 0 0 1}$ \\
Mean age $( \pm$ SD) & $71.8(15.6)$ & $62.4(19.0)$ & $<\mathbf{0 . 0 0 1}$ \\
Age groups (\%) & & & $<\mathbf{0 . 0 0 1}$ \\
$\quad<40$ years & $7(5.7)$ & $1395(17.9)$ & \\
$\quad$ 41-70 years & $37(30.3)$ & $3208(41.2)$ & \\
$>=71$ years & $78(63.9)$ & $3184(40.9)$ &
\end{tabular}

Hospital size

$<200$ acute care beds
$200-500$ beds
$>=501$ beds
Mean length of stay $( \pm S D)$
ength of stay
$<20$ days
$21-40$ days
$>=41$ days

Recent stay in intensive care (\%)

Hospitalisation ward (\%)

Medical ward
Surgical ward
Gynaecology/obstetrics
Intensive care unit
Medico-surgical

Recent surgery (\%)

Mean ASA score $( \pm S D)$

ASA (\%)

1 pt
$2-3$ pts
$4-5$ pts

McCabe/Jackson (\%)

Non fatal

Fatal within 5 years

Fatal within 6 months

Mean nursing workload $( \pm$ SD)

Mean Charlson index $( \pm \mathrm{SD})$

Charlson group (\%)

$$
\begin{aligned}
& 0-3 \text { pts } \\
& >=4 \text { pts }
\end{aligned}
$$

Co-morbidities (\%)

Diabetes mellitus
$23(18.3)$

$1994(24.8)$

$40(31.8)$

$2748(34.2)$

$63(50.0)$

$3301(41.0)$

20.5(22.2)

$11.4(41.0)$

$<0.001 *$

$<0.001$

$89(70.6) \quad 6990(86.9)$

$22(17.5)$

$677(8.4)$

15 (11.9)

374 (4.7)

$34(27.0)$

$1030(12.8)$

45 (35.7)

3192 (39.7)

$50(39.7)$

3219 (40.0)

$5(4.0)$

778 (9.7)

7 (5.6)

$285(3.5)$

19 (15.1)

$569(7.1)$

3292 (40.9)

$2.81(0.67)$

$2.33(0.89)$

4 (3.2)

$109(87.2)$

1587 (19.8)

$12(9.6)$

$5802(72.3)$

$634(7.9)$

$0.01 *$

$82(65.1) \quad 6143(76.4)$

36 (28.6) $\quad 1455$ (18.1)

8 (6.4) $\quad 445(5.5)$

204.0 (161.4) 168.3 (162.8)

$1.8(2.1)$

$1.2(1.8)$

$0.008^{*}$

$<0.001 *$

0.02

106 (84.1) $\quad 7267(90.4)$

$20(15.9) \quad 776(9.7)$

0.09

$<0.001$

$0.003^{*}$

0.09

$<0.001 *$

$<0.001^{*}$

$19(15.1) \quad 1074(13.4) \quad 0.57$

Table 1 Patient characteristics according to the presence of healthcare-associated urinary tract infection (UTI) $(n=8169)$, Swiss-NOSO Nationwide Prevalence Study, 2004

(Continued)

\begin{tabular}{llll}
\hline Immune suppression $^{\circ}$ & $26(20.6)$ & $1047(13.0)$ & $\mathbf{0 . 0 1}$ \\
Hemiplegia & $24(19.1)$ & $777(9.7)$ & $<\mathbf{0 . 0 0 1}$ \\
Dementia & $9(7.1)$ & $290(3.6)$ & $\mathbf{0 . 0 4}$ \\
\hline
\end{tabular}

ASA, American Society of Anesthesiologists; $(\%)=$ proportion of all surveyed patients according to number of the variable of interest among the study population; $S D=$ standard deviation; ${ }^{\circ}$ autoimmune disease, transplantation, hepatopathy, nephropathy, neoplasia.

co-morbidities). We used the same regression model to assess the independent association between the secondary outcome (use of UC) and various risk factors. For both models, we used a backward stepwise procedure by selecting all variables associated with a $\mathrm{p}<0.20$ at univariate and kept in the model all those significantly associated with the outcome $(\mathrm{p}<0.05)$. As we suspected that the pathophysiology of UTI differed according to gender and those exposed/not exposed to UC, we tested for an interaction between both variables and provided a stratified model on urinary catheter exposure/gender. We tested also for all interactions that were biologically plausible. Finally, we assessed the independent association between prior exposure to UC (secondary outcome) and the main confounders (gender, age, severity scores [McCabe, ASA], hospital length of stay, co-morbidities). The significance level was 0.05 (two-tailed). Statistical testing was performed, using SAS statistical software, version 9.2 (SAS Institute).

\section{Results}

A total of 8169 patients from 49 hospitals participated in the survey, representing a nationwide estimate of at least $30 \%$ of all hospitalised patients; 4313 (52.8\%) were female [12]. Among these, 1917 (23.5\%) were exposed to UC with an overall median duration of use of 4 days (interquartile range, 2-9 days). Of 126 patients overall who developed UTI (1.5\%; 85 female; median age, 77 years), 73 (58\%) had been exposed to UC within the week preceding UTI onset, while 53 (42\%) had no exposure. Sixty-two percent of all case report forms for UTI patients were maximally rated (6/6 points on the Likert scale) by observers and a further $25 \%$ with almost complete agreement (5/6 points). Females were at higher risk for UTI (odds ratio [OR], 2.1 [95\% confidence interval (CI), 1.4-3.1]). Four UTI episodes were classified as upper UTI or abscesses, and six were bacteraemic. We identified a total of 14 different causative pathogens, of which the most frequent in descending order were Escherichia coli, Proteus spp, Klebsiella spp, Enterobacter spp, and Enterococcus spp. On average, UTI was diagnosed 16 days after admission (range, 2 to $124 \mathrm{~d}$ ). Patient population characteristics stratified according to the occurrence of UTI are shown in Table 1. The 38 
episodes of asymptomatic urinary tract bacterial colonization were excluded according to our study protocol.

\section{Multivariate adjustment Overall UTI}

By multivariate logistic regression analysis with a random effect at the hospital level, independent factors associated with higher odds for UTI were prior exposure to UC (odds ratio, OR, 3.9 [95\% CI, 2.6-5.9]), female gender (OR, 2.1 [95\% CI, 1.4-3.1]), ASA score of $>2$ points (OR, 3.2 [95\% CI, 1.1-9.4], and prolonged hospital stay $>20$ days $(\mathrm{OR}, 1.9 \quad[95 \%$ CI, 1.4-3.2]. When female gender and prior exposure were combined with UC as one risk factor, the likelihood of UTI increased by 10.4-fold compared to the combination of male gender and no prior exposure to UC. Women not exposed to UC had a 3.4-fold risk of UTI compared to men not exposed to UC. The likelihood of UTI increased independently with age, ASA group, and the length of hospital stay, after adjustment on the main other confounders (Tables $2 \& 3$ ).

\section{UTI with and without prior UC exposure}

In the model assessing the likelihood of UTI stratified on prior exposure to UC (Table 2), the only factor significantly associated was a prolonged hospital stay $>$ 40 days, while female gender showed only a tendency for association. In the model stratified on no prior exposure to UC, female gender, hemiplegia, and a recent stay in intensive care all increased significantly the odds for UTI.

\section{UTI stratified by gender}

In the model assessing the likelihood of UTI stratified by gender (Table 3), prior exposure to UC was significantly associated with UTI for both, whereas the length of hospital stay was significantly associated with UTI for women, but not for men.

\section{Exposure to UC}

We investigated the variables associated with the use of UC after stratification by gender. There were no differences between genders according to exposure to UC. The following factors were independently associated with a higher odds for the use of UC: age $>70$ years; recent surgical intervention; ASA score $>4$ points; Charlson index $>4$ points; high McCabe classification; recent stay in intensive care; and hemiplegia.

\section{Discussion}

In this large study of patients hospitalised in Swiss acute care facilities, $25 \%$ were exposed to UC and $1.5 \%$ developed symptomatic UTI. Congruent with our results and other national and regional prevalence studies, a European report estimated a prevalence of nosocomial UTI of $1.65 \%$ (Table 4). Our findings mirror reports revealing a prevalence of UC use of $20.3 \%$ in emergency departments [8], $32 \%$ to $36 \%$ in acute care wards [5], and similar rates in most surveys conducted elsewhere (Table 4). The median duration of exposure to UC was also congruent with the literature, i.e., 2-4 days [18-41].

By contrast, we are not able to compare healthcareassociated UTI prevalence with prevalence encountered in the community. Scientific data on the incidence or prevalence of UTI in the Swiss general population are non-existent, while the literature provides only data in predefined populations, such as elderly men or diabetic patients. Moreover, different survey studies define UTI differently, e.g., by excluding or including asymptomatic colonization. However, according to rough data, the overall life-long incidence of UTI could be around 2-4\% for young males [42], 6.3\% for older Scandinavian males [43], and up to $20 \%$ for females. Among Saudi diabetic males, the prevalence might be as high as $7 \%$, whereas asymptomatic urinary tract colonization might be as high as $41 \%$ in diabetic women [44].

We found a significant association between UTI and UC use. However, the relation between prior exposure to UC and subsequent UTI was much less systematic than expected, and UC use preceded UTI in only $58 \%$ of cases. This does not appear to be unique to our study. In a European study reviewing 4.4 million admissions in 1999, 37.2\% of all UTI episodes did not reveal prior exposure to UC [4]. A proportion of $41 \%$ UTI without prior exposure to UC has been similarly evidenced in Italian hospitals [31], while Jespen et al. found $56.7 \%$ of patients with healthcare-associated UTI attributed to prior UC use [19]. These reports did not further explore the relative low frequency of UC use prior to UTI.

In our study population, the low rate of UTI may reflect the low UC utilization rates. This is not surprising. One explanation might be recent surgery and/or a short ICU stay as these patients are often exposed to UC and acquire UTI more frequently than those hospitalised on medical wards. According to survey definitions, UC use was only recorded when it lasted $>24 \mathrm{~h}$, but some patients undergoing surgery could have been exposed to UC for a shorter time, at least during surgery or ICU stay. Although it cannot be excluded that short duration catheterisation might predispose to subsequent UTI, this is unlikely given the low UTI incidence of only $2 \%$ [45] to $2.5 \%$ [46] at $24 \mathrm{~h}$ of UC use. Moreover, at least in the largest institution involved in the current study, this assumption would not be true [47]. Since 2001, UC during surgery is restricted to patients with a foreseen duration of more than $5 \mathrm{~h}$ or for arthroplasty surgery if the patient meets one of the following conditions: 
Table 2 Multivariate logistic regression models clustered on hospitals presenting independent factors associated with urinary tract infection stratified on prior exposure to urinary catheter, Swiss-NOSO Nationwide Prevalence Study, 2004

\begin{tabular}{|c|c|c|c|c|c|c|}
\hline \multirow[t]{3}{*}{ Variables } & \multicolumn{3}{|c|}{ Prior exposure to urinary catheter } & \multicolumn{3}{|c|}{ No prior exposure to urinary catheter } \\
\hline & \multicolumn{3}{|l|}{$(n=1917)$} & \multicolumn{3}{|c|}{$(n=5957)$} \\
\hline & Odds ratio & $95 \% \mathrm{Cl}$ & $P$ value & OR & $95 \% \mathrm{Cl}$ & $P$ value \\
\hline Age groups (\%) & & & 0.62 & & & $0.03^{*}$ \\
\hline$<40$ years & 1.00 & - & - & 1.00 & - & - \\
\hline $41-70$ years & 1.77 & $0.51-6.10$ & 0.36 & 1.03 & $0.31-3.45$ & 0.96 \\
\hline$>=71$ years & 1.84 & $0.54-6.26$ & 0.33 & 2.53 & $0.81-7.94$ & 0.11 \\
\hline Recent surgical intervention & & & 0.75 & & & 0.59 \\
\hline No & 1.00 & - & & 1.00 & - & \\
\hline Yes & 0.92 & $0.54-1.56$ & & 0.84 & $0.44-1.59$ & \\
\hline ASA score (\%) & & & $0.09 *$ & & & 0.39 \\
\hline $1 \mathrm{pt}$ & 1.00 & - & - & 1.00 & - & - \\
\hline $2-3$ pts & 7.21 & $0.96-54.35$ & 0.06 & 1.99 & $0.54-7.28$ & 0.30 \\
\hline $4-5 \mathrm{pts}$ & 4.52 & $0.51-39.74$ & 0.17 & 1.11 & $0.18-6.78$ & 0.91 \\
\hline Charlson group & & & 0.55 & & & 0.76 \\
\hline $0-3$ pts & 1.00 & - & & 1.00 & - & \\
\hline$>=4$ pts & 1.30 & $0.55-3.08$ & & 0.85 & $0.30-2.40$ & \\
\hline Length of stay & & & $0.01 *$ & & & $0.09 *$ \\
\hline$<20$ days & 1.00 & - & - & 1.00 & - & - \\
\hline 21-40 days & 1.88 & $0.92-3.85$ & 0.08 & 2.01 & $0.95-4.22$ & 0.07 \\
\hline$>=41$ days & 2.87 & $1.34-6.11$ & 0.006 & 2.12 & $0.84-5.35$ & 0.11 \\
\hline Recent stay in intensive care & & & 0.99 & & & $0.05^{*}$ \\
\hline No & 1.00 & - & & 1.00 & - & \\
\hline Yes & 1.00 & $0.58-1.73$ & & 2.30 & $1.01-5.20$ & \\
\hline McCabe/Jackson (\%) & & & 0.95 & & & 0.18 \\
\hline Non fatal & 1.00 & - & - & 1.00 & - & - \\
\hline Fatal within 5 years & 0.98 & $0.54-1.77$ & 0.95 & 1.71 & $0.88-3.31$ & 0.11 \\
\hline Fatal within 6 months & 1.15 & $0.45-2.93$ & 0.76 & 0.50 & $0.06-3.87$ & 0.50 \\
\hline Gender & & & $0.06^{*}$ & & & $0.001 *$ \\
\hline Male & 1.00 & - & & 1.00 & - & \\
\hline Female & 1.61 & $0.98-2.65$ & & 3.27 & $1.65-6.48$ & \\
\hline Hemiplegia & & & 0.78 & & & $0.03^{*}$ \\
\hline No & 1.00 & - & & 1.00 & - & \\
\hline Yes & 1.10 & $0.55-2.20$ & & 2.10 & $1.07-4.11$ & \\
\hline Immune suppression $^{\circ}$ & & & 0.67 & & & 0.45 \\
\hline No & 1.00 & - & & 1.00 & - & \\
\hline Yes & 1.18 & $0.54-2.58$ & & 1.42 & $0.57-3.51$ & \\
\hline
\end{tabular}

*Independent variables significantly (or slightly significantly) associated with urinary tract infection.

$A S A=$ American Society of Anesthesiologists; autoimmune disease, transplantation, hepatopathy, nephropathy, neoplasia.

age $>75$ years; ASA class $>3$ points; presence of morbid obesity or urinary incontinence [43,48]. Thus, only $15.7 \%$ of all orthopaedic surgery is performed with a UC in place. For postanaesthesia care, only $4.7 \%$ of all patients required bladder catheterisation without permanent insertion of a UC [46].
Another population prone to intermittent catheterisation are patients with neurogenic bladders who were not identified as such in our study protocol $[49,50]$. Of note, our study involved acute care settings with the voluntary exclusion of long-term care facilities or homes where most patients with neurogenic bladders are usually 
Table 3 Multivariate logistic regression models clustered on hospitals presenting independent factors associated with urinary tract infection stratified on gender, Swiss-NOSO Nationwide Prevalence Study, 2004

\begin{tabular}{|c|c|c|c|c|c|c|}
\hline \multirow[t]{2}{*}{ Variables } & \multicolumn{3}{|c|}{ Male $(n=3703)$} & \multicolumn{3}{|c|}{ Female $(n=4171)$} \\
\hline & Odds ratio & $95 \% \mathrm{Cl}$ & $P$ value & Odds ratio & $95 \% \mathrm{Cl}$ & $P$ value \\
\hline Age groups (\%) & & & $0.01 *$ & & & $0.10^{*}$ \\
\hline$<70$ years & 1.00 & - & & 1.00 & - & - \\
\hline$>=71$ years & 2.57 & $1.24-5.31$ & & 1.51 & $0.93-2.45$ & \\
\hline Recent surgical intervention & & & 0.78 & & & 0.43 \\
\hline No & 1.00 & - & & 1.00 & - & \\
\hline Yes & 1.11 & $0.55-2.21$ & & 0.82 & $0.49-1.35$ & \\
\hline ASA score (\%) & & & 0.30 & & & 0.47 \\
\hline$<4$ pts & 1.00 & - & & 1.00 & - & - \\
\hline $4-5 \mathrm{pts}$ & 0.52 & $0.15-1.81$ & & 0.73 & $0.31-1.73$ & \\
\hline Charlson group & & & 0.50 & & & 0.89 \\
\hline $0-3 \mathrm{pts}$ & 1.00 & - & & 1.00 & - & \\
\hline$>=4$ pts & 1.44 & $0.50-4.11$ & & 0.94 & $0.39-2.28$ & \\
\hline Length of stay & & & 0.57 & & & $<0.001 *$ \\
\hline$<20$ days & 1.00 & - & - & 1.00 & - & - \\
\hline 21-40 days & 0.86 & $0.26-2.92$ & 0.81 & 2.75 & $1.52-4.96$ & 0.001 \\
\hline$>=41$ days & 1.75 & $0.59-5.17$ & 0.31 & 2.89 & $1.41-5.92$ & 0.004 \\
\hline Recent stay in intensive care & & & 0.59 & & & $0.04^{*}$ \\
\hline No & 1.00 & - & & 1.00 & - & \\
\hline Yes & 0.79 & $0.35-1.81$ & & 1.83 & $1.03-3.24$ & \\
\hline McCabe classification (\%) & & & 0.84 & & & $0.14^{*}$ \\
\hline Non fatal & 1.00 & - & - & 1.00 & - & - \\
\hline Fatal within 5 years & 0.81 & $0.36-1.82$ & 0.61 & 1.70 & $0.99-2.91$ & 0.05 \\
\hline Fatal within 6 months & 1.11 & $0.31-4.04$ & 0.87 & 0.98 & $0.32-3.00$ & 0.98 \\
\hline Prior exposure to urinary catheter & & & $<0.001 *$ & & & $<0.001 *$ \\
\hline No & 1.00 & - & & 1.00 & - & \\
\hline Yes & 6.77 & $3.20-14.35$ & & 3.04 & $1.83-5.04$ & \\
\hline Hemiplegia & & & $0.08^{*}$ & & & 0.34 \\
\hline No & 1.00 & - & & 1.00 & - & \\
\hline Yes & 2.04 & $0.93-4.46$ & & 1.36 & $0.73-2.54$ & \\
\hline Immune suppression ${ }^{\circ}$ & & & 0.39 & & & 0.57 \\
\hline No & 1.00 & - & & 1.00 & - & \\
\hline Yes & 1.55 & $0.57-4.18$ & & 1.24 & $0.58-2.65$ & \\
\hline
\end{tabular}

*Independent variables significantly (or slightly significantly) associated with urinary tract infection.

ASA American Society of Anesthesiologists; autoimmune disease, transplantation, hepatopathy, nephropathy, neoplasia.

housed. Thus, the prevalence of neurogenic bladders in acute care settings should be low. We consider that we have avoided a major bias by including paraplegic patients in the study population. Finally, the exact risk of symptomatic UTI after one single intermittent catheterisation is unknown. Most of the literature on intermittent catheterisation concerns individuals with repeated catheterisation due to neurologic problems $[49,50]$. Among these patients with intermittent self-catheterisation during several years or months, the cumulative risk of UTI is reported to be as high as 50\% according to several surveys [50]. However, these patients cannot be compared with individuals with normal bladders who are only undergoing one single intermittent catheterisation for anaesthesiological or surgical reasons.

UTI can complicate urological interventions and be technically classified as surgical site infection. In a literature review, Slade reported approximately 19\% UTI after urological surgery [48]. We are unable to provide information on the proportion of "official urological patients" 
Table 4 Prevalence of urinary catheter use and/or symptomatic healthcare-associated urinary tract infection: reports in the peer-reviewed literature (January 1980-December 2012)

\begin{tabular}{|c|c|c|c|c|c|}
\hline Author/s & Population & Methodology & Catheter use & Infection & Remarks \\
\hline $\begin{array}{l}\text { Jepsen et al. } \\
\text { [19] } 1982\end{array}$ & $\begin{array}{l}40 \text { hospitals in eight } \\
\text { countries, } n=3899\end{array}$ & Point prevalence & $\begin{array}{l}10.1 \% \text { men, } \\
11.8 \% \text { women }\end{array}$ & $6.5 \%$ & Conducted in 1980 \\
\hline $\begin{array}{l}\text { Moro et al. } \\
\text { [20] } 1985\end{array}$ & $\begin{array}{l}130 \text { hospitals, } \\
\mathrm{n}=34,577\end{array}$ & Point prevalence & $9.4 \%$ & $2.1 \%$ & National prevalence survey in Italy, 1983 \\
\hline $\begin{array}{l}\text { Mertens et al. } \\
\text { [21] } 1987\end{array}$ & 106 hospitals, $n=8723$ & Point prevalence & $15.7 \%$ & $4.4 \%$ & $\begin{array}{l}\text { National prevalence survey in Belgium } 198470 \% \\
\text { surgery. Definition nosocomial: > 3rd day }\end{array}$ \\
\hline $\begin{array}{l}\text { Srámova et al. } \\
\text { [22] } 1988\end{array}$ & 23 hospitals, $n=12,260$ & Point prevalence & & $1.5 \%$ & Prevalence survey in Czechoslovakia, 1984 \\
\hline $\begin{array}{l}\text { Emmerson et al. } \\
\text { [23] } 1996\end{array}$ & 157 centres, $n=37,111$ & Survey & - & $2.4 \%$ & Prevalence survey in UK and Ireland, 1994 \\
\hline $\begin{array}{l}\text { Gastmeier et al. } \\
\text { [24] } 1997\end{array}$ & 72 hospitals, $n=14,966$ & Point prevalence & & $1.1 \%$ & National prevalence survey in Germany, 1994 \\
\hline $\begin{array}{l}\text { Scheel et al. } \\
\text { [25] } 1999\end{array}$ & $\begin{array}{l}\text { All acute care hospitals, } \\
\mathrm{n}=12,755\end{array}$ & Point prevalence & - & $2.2 \%$ & National prevalence survey in Norway, 1997 \\
\hline $\begin{array}{l}\text { Vaqué et al. } \\
\text { [26] } 1999\end{array}$ & $\mathrm{n}=51,674$ in 1997 & Point prevalence & - & $2.1 \%$ & National prevalence surveys in Spain, 1990-1997 \\
\hline $\begin{array}{l}\text { French Prevalence } \\
\text { Group [27] } 2000\end{array}$ & $\begin{array}{l}830 \text { hospitals, } \\
n=236,334\end{array}$ & Point prevalence & $9.6 \%$ & $1.6 \%$ & $\begin{array}{l}\text { National prevalence survey in France, } 1996, \\
\text { including psychiatric and long-term care wards }\end{array}$ \\
\hline $\begin{array}{l}\text { Eriksen et al. } \\
{[2] 2002}\end{array}$ & $\begin{array}{l}\text { Acute care hospitals, } \\
\mathrm{n}=11,500-12,500\end{array}$ & Point prevalence & - & $1.7-2.0 \%$ & $\begin{array}{l}\text { National prevalence surveys in Norway,2002 and } \\
2003\end{array}$ \\
\hline $\begin{array}{l}\text { Gikas et al. } \\
\text { [28] } 2002\end{array}$ & $n=3925$ & Point prevalence & $8.6 \%$ & $2.1 \%$ & Survey in 14 Greek hospitals, 1999 \\
\hline $\begin{array}{l}\text { Lizioli et al. } \\
\text { [29] } 2003\end{array}$ & $\begin{array}{l}\text { Public hospitals, } \\
\mathrm{n}=18,667\end{array}$ & Point prevalence & - & $1.6 \%$ & Prevalence survey in Lombardy, 2000 \\
\hline $\begin{array}{l}\text { Klavs et al. } \\
\text { [30] } 2003\end{array}$ & Acute care, $n=6695$ & Point prevalence & - & $1.2 \%$ & National prevalence survey in Slovenia, 2001 \\
\hline $\begin{array}{l}\text { Nicastri et al. } \\
\text { [31] } 2003\end{array}$ & $\begin{array}{l}15 \text { hospitals in Italy, } \\
\mathrm{n}=2165\end{array}$ & Point prevalence & $22.4 \%$ & $1.7 \%$ & All participating hospitals have $>400$ beds \\
\hline Wald et al. [5] 2005 & $\begin{array}{l}\text { Surgery, } n=111,330523 \\
\text { Medicare hospitals }\end{array}$ & $\begin{array}{l}\text { Retrospective } \\
\text { cohort study }\end{array}$ & $\begin{array}{l}32 \% \text { at } \\
\text { discharge day }\end{array}$ & - & Patients at discharge after hip replacement \\
\hline Tammelin [32] 2005 & 31 hospitals, $n=6369$ & & $16.5 \%$ & $1.65 \%$ & $\begin{array}{l}\text { Acute hospitals and long-term care facilities in } \\
\text { Sweden, } 2002\end{array}$ \\
\hline $\begin{array}{l}\text { Gravel et al. } \\
\text { [33] } 2007\end{array}$ & $n=5750$ & Point prevalence & $22 \%$ & $3.4 \%$ & National prevalence survey in Canada, 2002 \\
\hline $\begin{array}{l}\text { Hopmans et al. } \\
\text { [34] } 2007\end{array}$ & $\begin{array}{l}2 \text { tertiary Dutch } \\
\text { hospitals, } n=2661\end{array}$ & $\begin{array}{l}\text { Point prevalence } \\
\text { twice a year }\end{array}$ & - & $\begin{array}{l}2.3 \% \\
(1.2 \%-3.4 \%)\end{array}$ & 2001-2004. Obstetric wards excluded \\
\hline $\begin{array}{l}\text { Kevens et al. } \\
\text { [35] } 2007\end{array}$ & $\begin{array}{l}445 \text { US hospitals, } \\
\mathrm{n}=33,726,611\end{array}$ & $\begin{array}{l}\text { Throughout the } \\
\text { year } 2002\end{array}$ & - & $1.3 \%$ & Estimations for the USA \\
\hline $\begin{array}{l}\text { Pelizzer et al. } \\
\text { [36] } 2008\end{array}$ & $\begin{array}{l}21 \text { Italian hospitals, } \\
\mathrm{n}=6352\end{array}$ & Period prevalence & $25.2 \%$ & $2.2 \%$ & Prevalence study in Veneto region, Italy 2003 \\
\hline $\begin{array}{l}\text { van den Broek et al. } \\
\text { [37] } 2011\end{array}$ & 10 hospitals, $n=16,495$ & Period prevalence & $20.2 \%$ & $2.6 \%$ & Netherlands, acute care hospitals \\
\hline $\begin{array}{l}\text { Cairns et al. } \\
\text { [38] } 2011\end{array}$ & $\begin{array}{l}45 \text { acute care hospitals, } \\
\mathbf{n}=11,090\end{array}$ & Point prevalence & $20.3 \%$ & $2.0 \%$ & Scotland 2006, exclusion of obstetric patients \\
\hline $\begin{array}{l}\text { Cotter et al. } \\
\text { [39] } 2012\end{array}$ & $\begin{array}{l}69 \text { long-term care } \\
\text { facilities, } n=4,170\end{array}$ & Point prevalence & $5.6 \%$ & $1.5 \%$ & Long-term care facilities in Ireland, June 2010 \\
\hline $\begin{array}{l}\text { Askarian et al. } \\
\text { [40] } 2012\end{array}$ & $\begin{array}{l}8 \text { university hospitals, } \\
\mathrm{n}=3450\end{array}$ & Point prevalence & $23.1 \%$ & $1.4 \%$ & University hospitals in Shiraz, Iran \\
\hline $\begin{array}{l}\text { Health Protection } \\
\text { Agency [41] } 2012\end{array}$ & $\begin{array}{l}103 \text { healthcare facilities, } \\
\mathrm{n}=52,443\end{array}$ & Point prevalence & $18.8 \%$ & $1.1 \%$ & $\begin{array}{l}\text { English national point prevalence survey } \\
\text { preliminary data }\end{array}$ \\
\hline Present article & $\begin{array}{l}\text { Acute care hospitals, } \\
\mathrm{n}=8169\end{array}$ & $\begin{array}{l}\text { Period prevalence } \\
\text { Cluster-adapted }\end{array}$ & $24 \%$ & $1.5 \%$ & National prevalence survey in Switzerland, 2004 \\
\hline
\end{tabular}

* Only reports including at least 2000 patients admitted to acute care facilities are included. 
among all those undergoing surgery, because many Swiss surgical wards are mixed, especially in smaller hospitals, are mixed and care for urology and non-urology patients at the same time. Similarly, the same surgeons may often perform urologic and other surgical interventions during the same day. However, it is unlikely that these urologic patients represent a large group and that freshly-operated urological patients would have been exposed to UC for more than $24 \mathrm{~h}$. Specialized, urology-only, surgical wards did not exist in Switzerland at the time of the study and urology patients constitute a maximum of $10 \%$ of all surgical patients in many university centres. As summarised in Table 4, few national prevalence studies further stratify or report surgical specialties in detail. In the studies by Emmerson et al. [23] and Sramova et al. [22], the proportion of patients hospitalised on urological wards was only $3.9 \%$ and $2.4 \%$, respectively.

Our survey has several limitations. i) The study design was not targeted towards delineating the origin of UTI. The causal inference between exposure to UC and UTI seems logical, but is not proven sensu strictu. ii) Despite the large number of patients included, only 126 acquired UTI. Although positive in terms of infection control, these small numbers are associated with reduced statistical power that is recognized in the wide confidence intervals. iii) Results are limited to acute care sectors. Many patients exposed to UC in high-income countries live in nursing homes or other long-term care facilities where the prevalence is higher and UTI is one of the most frequent infections $[1,10]$. iv) Data related to antibiotic administration or urine acidification are lacking. This could be important as patients treated for other infections might be protected from UTI with antimicrobials covering Gram-negative rods, while antibiotic administration prior to hospital admission might equally have diminished the bacterial burden in the genitourinary system. To the best of our knowledge, no prevalence study has explored this theoretical relationship. Of note, in our study, symptomatic UTI occurred on average two weeks after hospital admission, but we ignore if patients already had asymptomatic urinary tract colonization before hospital admission. v) So far, only prevalence studies and personal clinical experience report a high proportion of UTI without prior exposure to UC. There are no prospective cohort studies or randomized trials to confirm this ubiquitous finding. We currently ignore if the ability to track the catheter as a risk factor for nosocomial UTI might be limited when using prevalence studies. vi) Our study protocol did not target differences in the clinical presentation between UTI with and without prior UC use. This may be a bias as the presence of UC may influence physicians in the work-up of fever, i.e., they might order urine cultures more often in patients with UC. This theoretical bias is likely to shift the proportion of UTI towards UC use.
In conclusion, exposure to UC is the most important risk factor for healthcare-associated UTI according to prevalence studies, but only for a proportion of all patients - at best two-thirds. This finding appears to be shared by other local or national prevalence studies. In our study, the separate analysis for UTI in the absence of prior UC use revealed only female gender [48], hemiplegia [5], and prolonged hospital stay as significant risk factors. The cumulative impact of other less inalienable risk factors should not be underestimated. Further research needs to place an emphasis on innovative strategies to address the specific issues of UTI in the absence of exposure to UC.

\section{Competing interests}

The authors declare that they have no competing interests.

\section{Authors' contributions}

The national prevalence study was designed by all authors. The study was primarily coordinated by HS and IU with support from all authors, including identifying patients and collecting data on cases. IU, HS and AG managed the data and performed the initial analysis of cases. IU, AG, and DP drafted the manuscript. All authors interpreted the results and revised the manuscript.

\section{Financial support}

This study was supported by the Swiss Federal Office for Public Health and unrestricted educational grants from Astra Zeneca, Bayer (Switzerland) AG, BBraun Medical AG, Beiersdorf AG, Ecolab GmBH, Mundipharma AG, and Schülke + Mayr AG

\section{Acknowledgments}

We are indebted to Rosemary Sudan for editorial assistance, Nadia Colaizzi for help in data processing and study organisation, and François Eggimann for information technology support. We thank Pierre-Alain Raeber for help and Stephan Harbarth for critical reading of the manuscript.

Parts of the study were presented at the 50th Interscience Conference on Antimicrobial Agents and Chemotherapy Congress in Boston, USA, on 15 September 2010 (abstract \#3192)

\section{Author details}

${ }^{1}$ Infection Control Programme and WHO Collaborating Centre on Patient Safety, University of Geneva Hospitals and Faculty of Medicine, 4 Rue Gabrielle Perret-Gentil, 1211, Geneva 14, Switzerland. ${ }^{2}$ Orthopaedic Surgery Department, University of Geneva Hospitals and Faculty of Medicine, Geneva, Switzerland. ${ }^{3}$ Department of Infectious Diseases, University of Geneva Hospitals and Faculty of Medicine, Geneva, Switzerland. ${ }^{4}$ Division of Infectious Diseases, University Hospital of Zurich, Zurich, Switzerland. ${ }^{5}$ Department of Infectious Diseases, University Hospital Bern, Bern, Switzerland. 'Department of Infectious Diseases, Central Institute of the Valais Hospitals, Sion, Switzerland. 'Department of Hospital Preventive Medicine, Centre Hospitalier Universitaire Vaudois and University of Lausanne, Lausanne, Switzerland. ${ }^{8}$ Department of Infectious Diseases, Ospedale Civico, Lugano, Switzerland. ${ }^{9}$ Division of Infectious Diseases, University of Basel Hospitals, Basel, Switzerland. ${ }^{10}$ Swiss Federal Office of Public Health, Bern, Switzerland. ${ }^{11}$ Current addresses: Department of Infectious Diseases and Hospital Hygiene, University of Zurich, Zurich, Switzerland. ${ }^{12}$ Current addresses: Hirslanden Clinics, Zurich, Switzerland. ${ }^{13}$ Current addresses: Public Health Service for the Canton of Vaud, Lausanne, Switzerland.

Received: 9 October 2012 Accepted: 14 January 2013

Published: 7 February 2013

\section{References}

1. Nicolle LE: Urinary tract infection in long-term-care facility residents. Clin Infect Dis 2000, 31:757-761.

2. Eriksen HM, Iversen BG, Aavitsland P: Prevalence of nosocomial infections in hospitals in Norway, 2002 and 2003. J Hosp Infect 2005, 60:40-45. 
3. Maki DG, Tambyah PA: Engineering out the risk for infection with urinary catheters. Emerg Infect Dis 2001, 7:342-347.

4. Bouza E, San Juan R, Muñoz P, Voss A, Kluytmans J: Co-operative Group of the European Study Group on Nosocomial Infections II: A European perspective on nosocomial urinary tract infections I. Clin Microbiol Infect 2001, 7:532-542.

5. Wald $H$, Epstein A, Kramer A: Extended use of indwelling urinary catheters in postoperative hip fracture patients. Med Care 2005, 43:1009-1017.

6. Foxman B: Epidemiology of urinary tract infections: incidence, morbidity, and economic costs. Dis Mon 2003, 49:53-70.

7. Tambyah PA, Knasinski V, Maki DG: The direct costs of nosocomial catheter-associated urinary tract infection in the era of managed care. Infect Control Hosp Epidemiol 2002, 23:27-31.

8. Gardam MA, Amihod B, Orenstein P, Consolacion N, Miller MA: Overutilization of indwelling urinary catheters and the development of nosocomial urinary tract infections. Clin Perform Qual Health Care 1998, 6:99-102.

9. Pittet D, Harbarth S, Ruef C, Francioli P, Sudre P, Pétignat C, Trampuz A, Widmer A: Prevalence and risk factors for nosocomial infections in four university hospitals in Switzerland. Infect Control Hosp Epidemiol 1999, 20:37-42.

10. Sax H, Hugonnet $S$, Harbarth $S$, Herrault $P$, Pittet D: Variation in nosocomial infection prevalence according to patient care setting: a hospital-wide survey. J Hosp Infect 2001, 48:27-32.

11. Sax H, Swiss-NOSO: Nationwide surveillance of nosocomial infections in Switzerland-methods and results of the Swiss Nosocomial Infection Prevalence Studies (SNIP) in 1999 and 2002. Ther Umsch 2004, 61:197-203.

12. Sax H, Pittet D, Swiss-NOSO Network: Interhospital differences in nosocomial infection rates: importance of case-mix adjustment. Arch Intern Med 2002, 162:2437-2442.

13. Owens WD, Felts JA, Spitznagel EL Jr: ASA physical status classifications: a study of consistency of ratings. Anesthesiology 1978, 49:239-243.

14. McCabe WR, Jackson GG: Gram negative bacteremia I: etiology and ecology. Arch Intern Med 1962, 110:847-855.

15. Charlson ME, Pompei $P$, Ales KL, MacKenzie CR: A new method of classifying prognostic comorbidity in longitudinal studies: development and validation. J Chronic Dis 1987, 40:373-383

16. Lambert $P$, Major L, Saint-Onge E, Saulnier D, Tilquin C, Vanderstraeten G: L'intégration de la planification des soins et de la mesure de la charge de travail au service des démarches scientifiques du soignant et du gestionnaire: la méthode PRN. In Les systèmes de mesure de la charge de travail en soins infirmiers. Edited by Thibault C. Montréal, Canada: Association des Hôpitaux du Québec; 1990:189-194.

17. Garner JS, Jarvis WR, Emori TG, Horan TC, Hughes JM: CDC definitions for nosocomial infections, 1988. Am J Infect Control 1988, 16:128-140.

18. Warren JW: Catheter-associated urinary tract infections. Int J Antimicrob Agents 2001, 17:299-303

19. Jepsen OB, Larsen SO, Dankert J, Daschner F, Grönroos P, Meers PD, Nyström B, Sander J: Urinary-tract infection and bacteraemia in hospitalized medical patients - a European multicentre prevalence survey on nosocomial infection. J Hosp Infect 1982, 3:241-252.

20. Moro ML, Stazi MA, Marasca G, Greco D, Zampieri A: National prevalence survey of hospital-acquired infections in Italy, 1983. J Hosp Infect 1986, 8:72-85.

21. Mertens R, Kegels G, Stroobant A, Reybrouck G, Lamotte JM, Potvliege C, Van Casteren V, Lauwers S, Verschraegen S, Wauters G, et al: The national prevalence survey of nosocomial infections in Belgium, 1984. J Hosp Infect 1987, 9:219-229.

22. Srámova H, Bartonova A, Bolek S, Krecmerova M, Subertova V: National prevalence survey of hospital-acquired infections in Czechoslovakia. J Hosp Infect 1988, 11:328-334.

23. Emmerson AM, Enstone JE, Griffin M, Kelsey MC, Smyth ET: The Second National Prevalence Survey of infection in hospitals-overview of the results. J Hosp Infect 1996, 32:175-190.

24. Gastmeier P, Kampf G, Wischnewski N, Schumacher M, Daschner F, Rüden $\mathrm{H}$ : Importance of the surveillance method: national prevalence studies on nosocomial infections and the limits of comparison. Infect Control Hosp Epidemiol 1999, 20:124-127.

25. Scheel O, Stormark M: National prevalence survey on hospital infections in Norway. J Hosp Infect 1999, 41:331-335.
26. Vaqué J, Rossello J, Arribas JL: Prevalence of nosocomial infections in Spain: EPINE study 1990-1997. J Hosp Infect 1999, 43:105-111.

27. The French Prevalence Group: Prevalence of nosocomial infections in France: results of the nationwide survey in 1996. J Hosp Infect 2000, 46:186-193.

28. Gikas A, Pediaditis J, Papadakis JA, Starakis J, Levidiotou S, Nikolaides P, Kioumis G, Maltezos E, Lazanas M, Anevlavis E, Roubelaki M, Tselentis Y, Greek Infection Control Network: Prevalence study of hospital-acquired infections in 14 Greek hospitals: planning from the local to the national surveillance level. J Hosp Infect 2002, 50:269-275.

29. Lizioli A, Privitera G, Alliata E, Antonietta Banfi EM, Boselli L, Panceri ML, Perna MC, Porretta AD, Santini MG, Carreri V: Prevalence of nosocomial infections in Italy: result from the Lombardy survey in 2000. J Hosp Infect 2003, 54:141-148.

30. Klavs I, Bufon Luznik T, Skerl M, Grgic-Vitek M, Lejko Zupanc T, Dolinsek M, Prodan V, Vegnuti M, Kraigher A, Arnez Z: Slovenian Hospital-Acquired Infections Survey Group: Prevalence of and risk factors for hospitalacquired infections in Slovenia - results of the first national survey, 2001. J Hosp Infect 2003, 54:149-157.

31. Nicastri E, Petrosillo N, Martini L, Larosa M, Gesu GP, Ippolito G: Prevalence of nosocomial infections in 15 Italian hospitals: first point prevalence study for the INF-NOS project. Infection 2003, 31:10-15.

32. Tammelin A: Urinary catheters and antibiotic treatment, Guidelines adherence could be better. Lakartidningen 2005, 102:378-381.

33. Gravel D, Taylor G, Ofner M, Johnston L, Loeb M, Roth VR, Stegenga J, Bryce E: Canadian Nosocomial Infection Surveillance Program, Matlow A: Point prevalence survey for healthcare-associated infections within Canadian adult acute-care hospitals. J Hosp Infect 2007, 66:243-248.

34. Hopmans TE, Blok HE, Troelstra A, Bonten MJ: Prevalence of hospitalacquired infections during successive surveillance surveys conducted at a university hospital in the Netherlands. Infect Control Hosp Epidemiol 2007, 28:459-465.

35. Klevens RM, Edwards JR, Richards CL Jr, Horan TC, Gaynes RP, Pollock DA, Cardo DM: Estimating health care-associated infections and deaths in U. S. hospitals, 2002. Public Health Rep 2007, 122:160-166.

36. Pellizzer G, Mantoan P, Timillero L, Allegranzi B, Fedeli U, Schievano E, Benedetti P, Saia M, Sax H, Spolaore P: Prevalence and risk factors for nosocomial infections in hospitals of the Veneto region, north-eastern Italy. Infection 2008, 36:112-119.

37. van den Broek PJ, Wille JC, van Benthem BH, Perenboom RJ, van den Akkervan Marle ME, Niël-Weise BS: Urethral catheters: can we reduce use? BMC Urol 2011, 11:10.

38. Cairns S, Reilly J, Stewart S, Tolson D, Godwin J, Knight P: The prevalence of health care-associated infection in older people in acute care hospitals. Infect Control Hosp Epidemiol 2011, 32:763-767.

39. Cotter M, Donlon S, Roche F, Byrne H, Fitzpatrick F: Healthcare-associated infection in Irish long-term care facilities: results from the First National Prevalence Study. J Hosp Infect 2012, 80:212-216.

40. Askarian $M$, Yadollahi M, Assadian O: Point prevalence and risk factors of hospital acquired infections in a cluster of university-affiliated hospitals in Shiraz Iran. J Infect Public Health 2012, 5:169-176.

41. Hopkins S, Shaw K, Simpson L: English national point prevalence survey on healthcare-associated infections and antimicrobial use. London, UK: Health ProtectionAgency; 2011. http://www.hpa.org.uk/webc/HPAwebFile/ HPAweb_C/1317134304594.

42. Kyrklund K, Taskinen S, Rintala RJ, Pakarinen MP: Lower urinary tract symptoms from childhood to adulthood: A population bases study of 594 Finnish individuals 4 to 26 years old. J Urol 2012, 188:588-593.

43. Malmsten UGH, Milsom I, Molander U, Norlen LJ: Urinary incontinence and lower urinary tract symptoms: an epidemiological study of men aged 45 to 99 years. J Urol 1997, 158:1733-1737.

44. Al-Rubeaan KA, Moharrem O, Al-Nageb D, Hassan A, Rafiullah MRM: Prevalence of urinary tract infection and risk factors among Saudi patients with diabetes. World J Urol 2012, doi:10.10077s00345-012-0934-x.

45. Garibaldi RA, Mooney BR, Epstein BJ, Britt MR: An evaluation of daily bacteriologic monitoring to identify preventable episodes of catheterassociated urinary tract infection. Infect Control 1982, 3:466-70.

46. Vieira FA: Nursing actions to prevent urinary tract infection associated with long-standing bladder catheter. Einstein 2009, 7:372-375. 
47. Stéphan F, Sax H, Wachsmuth M, Hoffmeyer P, Clergue F, Pittet D: Reduction of urinary tract infection and antibiotic use after surgery: a controlled, prospective, before-after intervention study. Clin Infect Dis 2006, 42:1544-1551.

48. Slade N: Postoperative urinary tract infections in urology and gynaecology: a review. J R Soc Med 1980, 3:739-743.

49. Newman DK, Willson MM: Review of intermittent catheterization and current best practices. Urologic Nurs 2011, 31:12-28.

50. Wyndaele Jj: Complications of intermittent catheterization: their prevention and treatment. Spinal Cord 2002, 40:536-541.

doi:10.1186/2047-2994-2-5

Cite this article as: Uçkay et al:: High proportion of healthcare-

associated urinary tract infection in the absence of prior exposure to urinary catheter: a cross-sectional study. Antimicrobial Resistance and Infection Control 2013 2:5.

\section{Submit your next manuscript to BioMed Central and take full advantage of:}

- Convenient online submission

- Thorough peer review

- No space constraints or color figure charges

- Immediate publication on acceptance

- Inclusion in PubMed, CAS, Scopus and Google Scholar

- Research which is freely available for redistribution 